\title{
Clinical guideline: status epilepticus in children and adults
}

\author{
Alejandro Olmos-López ${ }^{1}$, Jorge Ibarra-Aguilar², José O. Cornelio-Nieto ${ }^{3}$, Luis A. Ocaña-Hernández ${ }^{4}$, \\ Mario A. Márquez-Amaya ${ }^{5}$, Norberto Luna-López ${ }^{6}$, Juan C. Reséndiz-Aparicio ${ }^{7}$ and \\ Ildefonso Rodríguez-Leyva ${ }^{8}$
}

${ }^{1}$ Hospital General de Cuernavaca "Dr. José G. Parres," Morelos; ${ }^{2}$ Hospital del Niño del DIF, Pachuca, Hidalgo; ${ }^{3}$ Hospital de Alta Especialidad del Niño "Dr. Rodolfo Nieto Padrón", Villahermosa, Tabasco; ${ }^{4}$ Unidad Médica de Alta Especialidad H.E.No.71, IMSS Torreón, Coahuila; ${ }^{5}$ Hospital Regional, Delicias, Chihuahua; ${ }^{6}$ Facultad de Medicina de Minatitlan, Veracruz; ${ }^{7} P P E$, Instituto Nacional de Neurología y Neurocirugía Dr. Manuel Velasco Suárez y Hospital Psiquiátrico Infantil Dr. Juan N. Navarro, Mexico City; ${ }^{8}$ Hospital Central "Dr. Ignacio Morones Prieto" San Luis Potosí, San Luis Potosí, Mexico

\begin{abstract}
A generalized epileptic seizure lasting 5 or more minutes, or the presence of two or more seizures without recovering consciousness within $30 \mathrm{~min}$, or a focal seizure that persists for $>10 \mathrm{~min}$, or with altered consciousness lasting for 60 min or more is called status epilepticus (SE). It can be classified into generalized and focal and motor and non-motor. Its etiology may or may not be recognized. The electroencephalographic pattern shows focal or generalized persistent epileptic activity. It is a dangerous situation, which requires algorithmic management from the time it is detected in the emergency room and if required, in intensive care. In-hospital management would include the initial $A B C D E$, hypertonic glucose solution, and thiamin; if hypoglycemia was detected. Lorazepam (midazolam [MDZ] or diazepam) to stop seizures, followed by phenytoin, valproate, or levetiracetam in impregnation and maintenance. If the SE persists for more than an hour, the patient will be admitted to an intensive care unit with intubation and continuous administration of MDZ, propofol or thiopental with continuous monitoring. If it does not yield with two drugs, it is called refractory epileptic status, and if it continues for $24 \mathrm{~h}$ or more, it is recognized as super-refractory. A third of patients die.
\end{abstract}

Key words: Status epilepticus. Seizures. Focal. Generalized. Motor. Acute treatment.

\section{How is status epilepticus (SE) defined?}

The ILAE proposes an operational definition as a generalized epileptic seizure in children and adults that lasts 5 or more minutes, two or more seizures without recovering awareness within 30 min (here, we include the majority of generalized epileptic seizures). It is a condition that results from a failure in initiating the inhibitory mechanisms responsible for terminating an epileptic seizure and the persistence of mechanisms that favor the extension of a seizure.
A generalized motor SE is defined as 5 or more minutes of generalized motor activity, or recurrent seizure without returning to baseline. These represent $45-75 \%$ of all epileptic states.

There is insufficient information about focal SE with altered level of awareness. However, it has been proposed to define it as an epileptic seizure that lasts 10 min or two or more epileptic seizures without recovering a state of awareness within $60 \mathrm{~min}$. For absence SE, there is not enough scientific evidence to define the times, but it has been proposed that it be

\section{Correspondence:}

Ildefonso Rodríguez-Leyva

E-mail: ilrole@yahoo.com.mx
Available online: 12-04-2019 Rev Mex Neuroci. 2019;20(2):110-115 www.revmexneurociencia.com 1665-5044/@ 2019. Academia Mexicana de Neurología A.C. Published by Permanyer México. This is an Open Access article under the CC BY-NC-ND license (http://creativecommons.org/licenses/by-nc-nd/4.0/). 
Table 1. Axis 1 - SE classification

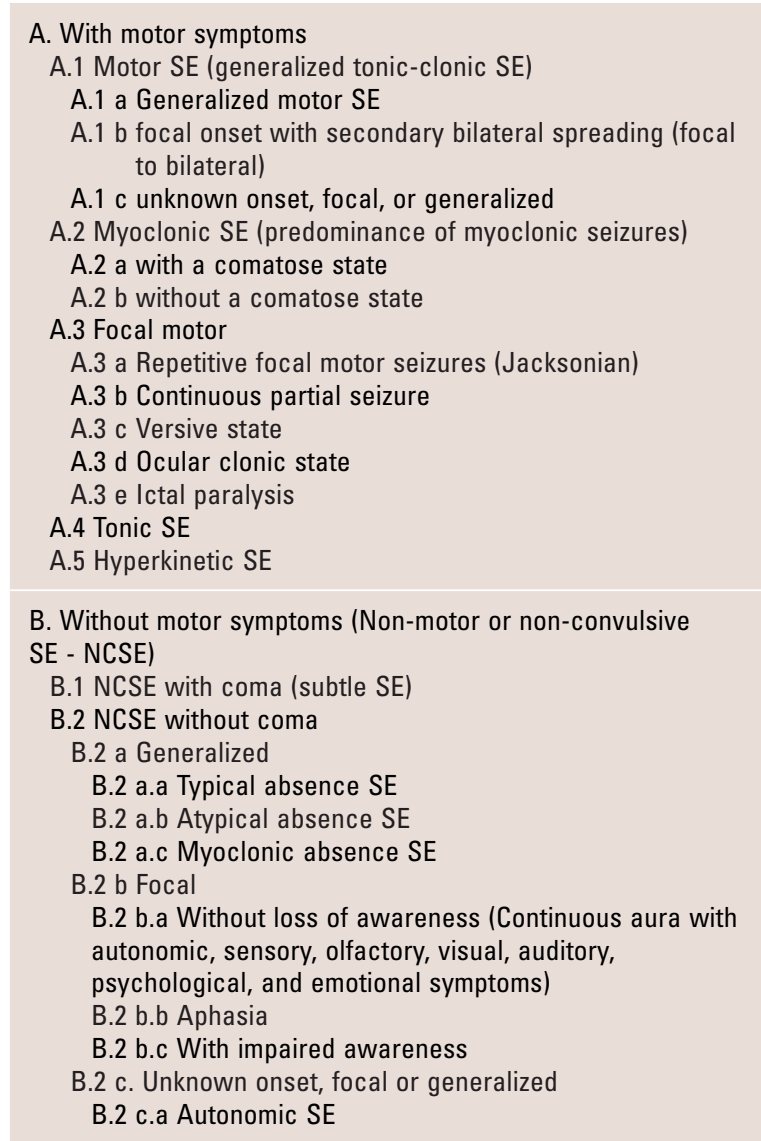

SE: status epilepticus.

Table 2. Axis 2 - Etiology

Known cause (symptomatic)
Acute
Remote
Progressive
SE in defined electroclinical syndromes
Of unknown cause (cryptogenic)

SE: status epilepticus

defined as an absence epileptic seizure lasting 1015 min or more.

\section{How is SE classified?}

It can be classified based on four main axes, which cannot always be determined: semiology, etiology, electroencephalographic correlation, and age.

Axis 1 (semiology): two criteria are considered: the presence or absence of motor symptoms and signs and the degree (qualitative or quantitative) of altered awareness (Table 1).
Table 3. Axis 3 - Electroencephalographic correlation

1. Location: generalized (including bilateral synchronic patterns), lateralized, bilateral, independent, and multifocal

2. By electric pattern: periodic discharges, rhythmic delta activity, or subtypes of a paroxysmal pattern of spike-wave and sharp-wave

3. By morphology: wave acuteness, triphasic waves, absolute and relative amplitude, and polarity

Table 4. Axis 4 - Age

Neonatal: 0-30 days

Lactating: 1 month-2 years

Infancy: 2 years-12 years

Adolescence and adulthood: 12 years- 59 years

Senile: $>60$ years

Axis 2 (etiology): on occasion, it is difficult to determine the cause of the SE, so they are divided into two groups: known and unknown cause (Table 2).

Axis 3 (electroencephalographic correlation): most of the first or second level hospitals do not have electroencephalogram (EEG) equipment, but if the study can be carried out, it should be done immediately. Based on descriptive series and consensus, we can describe six electrical activity patterns (Table 3).

Axis 4 (age): important axis since the clinical manifestations of SE can vary (Table 4).

\section{What are the pre-hospitalization measures in SE management?}

Pre-hospitalization measures begin with the family and generally, with paramedics that will help maintain the airway permeable, avoid trauma (placing the patient in a place where he will not get hurt), and place the head on its side. Ideally, the paramedic or extra-hospital first contact physician must be prepared to give cardiopulmonary resuscitation if the patient presents asystole and/or apnea.

The paramedic or first contact physician can administer a standard dose (Table 5) diazepam or lorazepam by intrarectal, nasal, intramuscular, or intravenous administration.

As soon as the situation is stabilized in the quickest manner possible, the patient must be sent to a hospital that, ideally, will have an adequate service of emergency care and intensive care.

Steps:

- Immediate protection of the airway, ensure gaseous exchange and place the head properly (avoid snoring 
Table 5. Benzodiazepines In SE

\begin{tabular}{|c|c|c|}
\hline & Doses in adults & Doses in children \\
\hline Lorazepam & $\begin{array}{l}0.1 \mathrm{mg} / \mathrm{kg} \text { IV up } \\
\text { to } 4 \mathrm{mg}\end{array}$ & $0.04 \mathrm{mg} / \mathrm{kg}$ IV \\
\hline MDZ & $\begin{array}{l}0.2 \mathrm{mg} / \mathrm{kg} \text { IM or } \\
\text { IV up to } 10 \mathrm{mg}\end{array}$ & $\begin{array}{l}\text { Heavier than } 40 \mathrm{~kg}: 0.2 \mathrm{mg} / \mathrm{kg} \\
\text { up to } 10 \mathrm{mg} \\
\text { Lighter than } 40 \mathrm{~kg}: 0.2 \mathrm{mg} / \mathrm{kg} \\
\text { up to } 5 \mathrm{mg}\end{array}$ \\
\hline Diazepam & $\begin{array}{l}0.15 \mathrm{mg} / \mathrm{kg} \mathrm{IV} \\
\text { up to } 10 \mathrm{mg} \text { IV }\end{array}$ & $\begin{array}{l}\text { IV } 0.3 \mathrm{mg} / \mathrm{kg} \text { up to } 5 \mathrm{mg} \text { in } \\
\text { younger than } 5 \text { years and } \\
10 \mathrm{mg} \text { in older than } 5 \text { years } \\
\text { Rectal: } 0.5 \mathrm{mg} / \mathrm{kg} \text {. From } 1 \text { to } \\
3 \text { years } 5 \mathrm{mg} \text {, older } \\
\text { than } 3 \text { years } 10 \mathrm{mg} \\
\text { standard dose }\end{array}$ \\
\hline
\end{tabular}

SE: status epilepticus, MDZ: midazolam

and lingual obstruction), and if necessary and available, administer oxygen.

- Monitor vital signs.

- Test for glycemia using a Destrostix, if possible.

- Administer a standard dose (child or adult) of benzodiazepine by rectal, nasal, intramuscular, or intravenous administration.

\section{What are the initial measures that must be taken for the management of SE?}

0-5 min:

- ABCDE.

- Duration.

- Oxygen.

- Monitorization.

- Determination of glycemia (in adults, if glucose was lower than $60 \mathrm{mg}$, administer thiamine, and $50 \mathrm{ml}$ $50 \%$ glucose; for children older than 2 years, $2 \mathrm{ml} / \mathrm{kg}$ of $25 \%$ glucose solution.

- Place venous access and take blood for laboratory tests (complete blood count, serum electrolytes, drug serum levels, and toxicologic screen).

- If it is considered necessary, place the urinary catheter.

- Complete diagnostic approach: continuous EEG, computed axial tomography, lumbar puncture, and magnetic resonance imaging (preferred over cranial computed tomography).

\section{What is the initial pharmacologic treatment to manage generalized motor SE?}

Benzodiazepines are the first-line treatment for the management of SE (Table 5).
Others:

- Phenytoin (fosphenytoin): $20 \mathrm{mg} / \mathrm{kg}$ IV to $50 \mathrm{mg} / \mathrm{min} /$ physiological solution

- Phenobarbital: $20 \mathrm{mg} / \mathrm{Kg}$ IV $(5-10 \mathrm{mg} / \mathrm{kg}$ can be added)

- Valproate (VPA): $20-40 \mathrm{mg} / \mathrm{kg}$ IV

- Levetiracetam: $60 \mathrm{mg} / \mathrm{Kg}$ (1-3 g) IV

- Lacosamide: $100 \mathrm{mg}$ IV every $6 \mathrm{~h}$

\section{What is the second-line pharmacologic treatment to manage generalized motor SE?}

Second-line drugs or urgent control therapy are added when SE has been established, that is, when benzodiazepines alone have not been effective in subverting the crisis ${ }^{1,2,4}$.

In adults, intravenous levetiracetam, phenytoin, or VPA can be used (level A) $)^{1,2}$. In children, the guidelines from the American Epilepsy Society state that there is insufficient evidence to evaluate phenytoin and levetiracetam as second-line treatments (level $\mathrm{U}$ ), however valproic acid has similar efficacy and better tolerability than intravenous phenobarbital (level B) ${ }^{3}$. The US National Institutes of Health have implemented a protocol for the treatment of SE comparing phenytoin, VPA, and levetiracetam in children and adults, contributing relevant information about these drugs (level C) ${ }^{5}$.

In some studies ${ }^{6,7}$, phenytoin, and fosphenytoin are the most commonly used drugs if SE persists in spite of benzodiazepine administration. A recent meta-analy$\mathrm{sis}^{8}$ of drugs administered for SE refractory to benzodiazepines demonstrated the efficacy of phenytoin $(50 \%)$, levetiracetam $(69 \%)$, phenobarbital $(74 \%)$, and VPA (76\%) (all C).

\section{What is the initial pharmacologic treatment for other SE (Focal and non-motor)?}

Non-motor SE (NCSE) is an entity that is difficult to recognize clinically due to its heterogeneity. Its diagnosis results from its suspicion, mainly due to an altered state of consciousness and persistence of clinical changes after a convulsive event or convulsive epileptic state has finished. NCSE must be considered for any patients with altered consciousness presenting one or more of these situations: coma, lethargy, and confusion. For focal SE: Todd's paralysis, which is a neurologic focal deficit of the last hours or days, especially if it is after a seizure. 
Table 6. First line drugs in SE treatment

\begin{tabular}{|l|l|l|l|}
\hline AED & Doses in adults & Doses in children & Infusion speed \\
\hline Phenytoin & $20 \mathrm{mg} / \mathrm{kg} \mathrm{IV}$ & 18 a $20 \mathrm{mg} / \mathrm{kg} \mathrm{IV}$ up to $1 \mathrm{~g}$ & $1 \mathrm{mg} / \mathrm{kg} / \mathrm{min}$ for at least $20 \mathrm{~min}$ \\
\hline Phenobarbital* & $20 \mathrm{mg} / \mathrm{kg} \mathrm{IV}$ & 15 a $20 \mathrm{mg} / \mathrm{kg} \mathrm{IV}$ up to $1 \mathrm{~g}$ & $1 \mathrm{mg} / \mathrm{kg} / \mathrm{min}$ for at least $20 \mathrm{~min}$ \\
\hline Valproic acid & $20-40 \mathrm{mg} / \mathrm{kg} \mathrm{IV}$ & $20-40 \mathrm{mg} / \mathrm{kg} \mathrm{IV} \mathrm{up} \mathrm{to} 1.5 \mathrm{~g}$ & Infusion for $15 \mathrm{~min}$ \\
\hline Levetiracetam & $1 \mathrm{~g}-3 \mathrm{~g} / \mathrm{kg} \mathrm{IV}$ & $20-60 \mathrm{mg} / \mathrm{kg} \mathrm{IV} \mathrm{up} \mathrm{to} 2.5 \mathrm{~g}$ & Infusion for $15 \mathrm{~min}$ \\
\hline Lacosamide & $200-400 \mathrm{mg} \mathrm{IV}$ & No established pediatric dose & Infusion for $15 \mathrm{~min}$ \\
\hline
\end{tabular}

AED: automated external defibrillator. ${ }^{*}$ Not available in Mexico.

Table 7. Second-line drugs in SE treatment

\begin{tabular}{|l|l|l|l|}
\hline Patient & Intervention & Comparison & Result \\
\hline $\begin{array}{l}\text { Pediatric patient with } \\
\text { tonic-clonic SE }\end{array}$ & Second line drugs & $\begin{array}{l}\text { Phenytoin, } \\
\text { VPA, } \\
\text { Levetiracetam, } \\
\text { Phenobarbital }\end{array}$ & $\begin{array}{l}\text { Phenytoin, fosphenytoin, and Levetiracetam (Level U). } \\
\text { VPA, phenobarbital (Level B) }\end{array}$ \\
\hline $\begin{array}{l}\text { Adult patient with } \\
\text { tonic-clonic SE }\end{array}$ & & Levetiracetam, phenytoin or VPA (level A) \\
\hline \begin{tabular}{l} 
SE: status epilepticus, VPA: valproate. \\
\hline
\end{tabular} & & \\
\hline
\end{tabular}

It presents in up to $30 \%$ of patients with previous convulsive SE and requires discovery of compatible electroencephalic changes persisting for $>10 \min ^{10,11}$.

\section{Diagnostic criteria}

- Alterations in consciousness or other neurological deficit.

- Epileptiform EEG: discrete epileptic paroxysms or continuous discharges.

- Response to anticonvulsants: clinical or electroencephalographic.

The most frequent types of NCSE are the focal non-convulsive, the absence status, the continuous partial epilepsy, the continuous aura, persistent hemiparesis, and others of lesser frequency. It is classified as follows:

- Comatose form: generalized or focal (must be treated if it lasts $>30 \mathrm{~min}$ ). May or may not be preceded by a convulsive SE.

- NCSE proper form: absence status (typical absence, atypical absence, and late-onset absence), treatment is recommended after $15 \mathrm{~min}$. Focal SE, with or without altered consciousness, initiating treatment is recommended after $10 \mathrm{~min}$.

For treatment, there are two recommended methods:
- Aggressive treatment, similar to management of convulsive SE, preferred for patients that have had a symptomatic convulsive event (after an event of asphyxia or acute hypoxia, perinatal hypoxic encephalopathy, Cardiovascular disease, automated external defibrillator suppression, etc.) since the morbimortality is high in these patients.

- For the rest of the primary non-convulsive SE, morbimortality is low and less aggressive management, using oral or parenteral administration is preferred, which reduces the morbimortality inherent in the use of central nervous system depressant drugs used to manage SE.

Instructions for administration (IV) and pharmacokinetics of anti-epileptic drugs in refractory SE:

MDZ 0.2-0.3 mg/kg or $4 \mathrm{mg} / 2 \mathrm{~min}, 0.1-0.5 \mathrm{mg} / \mathrm{kg} /$ hour, 0.2-1 $\mu \mathrm{g} / \mathrm{ml}$ in bolus. Propofol $1-2 \mathrm{mg} / \mathrm{kg}$. Slowly, $5-10 \mathrm{mg} / \mathrm{kg} / \mathrm{h}$. Thiopental $100-200 \mathrm{mg} 30 \mathrm{~s} 3-5 \mathrm{mg} / \mathrm{kg} / \mathrm{h}$, $25-50 \mu \mathrm{g} / \mathrm{ml}$ in bolus, followed by $50 \mathrm{mg}$ every 2-3 minutes until the ES is controlled. Ketamine $0.5-4.5 \mathrm{mg} /$ $\mathrm{Kg}$ (up to $5 \mathrm{mg} / \mathrm{Kg} / \mathrm{h}$ ).

The patient must be closely monitored to avoid hypotension, sepsis, atelectasis, pneumonia, or cerebral venous thrombosis, to the extent possible. On occasion, parenteral feeding for the patient may be necessary. 
Table 8. Possibilities of success and complications with drugs (modified from Bleck, 1999) ${ }^{9}$

\begin{tabular}{|l|c|c|c|c|}
\hline AED & Success (\%) & APNEA (\%) & Hypotension (\%) & Arrhythmias (\%) \\
\hline LRZ & 65 & 14 & 28 & 12 \\
\hline PB & 58 & 13 & 34 & 3 \\
\hline DZP + PHT & 56 & 19 & 33 & 2 \\
\hline PHT & 44 & 11 & 29 & 9 \\
\hline Mean & 55 & & & \\
\hline
\end{tabular}

AED: antiepileptic drugs

Table 9. Levels of Evidence of drugs in SE (modified from Yasiry, et al.,2014) ${ }^{10}$

\begin{tabular}{|c|c|}
\hline & $\begin{array}{l}\text { Evidence and level of } \\
\text { recommendation }\end{array}$ \\
\hline $\begin{array}{l}\text { Treatment for SE } \\
\text { Lorazepam } \\
\text { Midazolam } \\
\text { Diazepam } \\
\text { Phenytoin } \\
\text { Phenobarbital } \\
\text { Valproato } \\
\text { Levetiracetam }\end{array}$ & $\begin{array}{l}\text { Class I/Level A } \\
\text { Class I/Level A } \\
\text { Class Ila/Level A } \\
\text { Class IIb/Level A } \\
\text { Class IIb/Level A } \\
\text { Class IIb/Level A } \\
\text { Class IIb/Level A }\end{array}$ \\
\hline $\begin{array}{l}\text { Treatment for RSE } \\
\text { Midazolam } \\
\text { Propofol } \\
\text { Thiopental } \\
\text { Valproato } \\
\text { Levetiracetam } \\
\text { Phenytoin } \\
\text { The PPE recommends reviewing the } \\
\text { complete guide }\end{array}$ & $\begin{array}{l}\text { Class Ila/Level B } \\
\text { Class IIb/Level B } \\
\text { Class IIb/Level B } \\
\text { Class IIb/Level B } \\
\text { Class IIb/Level B } \\
\text { Class IIb/Level B } \\
\text { R-PPE }\end{array}$ \\
\hline
\end{tabular}

SE: status epilepticus

\section{9. ¿When is a generalized convulsive SE considered to be refractory to treatment?}

Refractory SE is defined as a generalized epileptic seizure that persists despite the use of two anti-epileptic drugs: at least one first-line drug (benzodiazepine) and another second-line drug. The super-refractory SE is defined as a SE that continues or recurs in $24 \mathrm{~h}$ or more once anesthesia has been initiated, when it is removed, or when it is completely terminated. It can also be considered when there are clinical or encephalographic seizures after benzodiazepine treatment and an adequately selected anti-epileptic drug.

Predictors of a Refractory SE:

- Non-structural causes: hypoxia, toxic-metabolic, and infection.

- Hyponatremia in the previous $24 \mathrm{~h}$.
- Delay in diagnosis and treatment.

- Non-convulsive or subtle SE.

- Convulsive focal onset seizures.

- Young patient ${ }^{11-18}$. Complications:

- Prolonged ventilator use and its complications.

- Refractory bradycardia with metabolic acidosis.

- Hyperlipidemia

- Fatty liver

Triggering factors:

- Sepsis, assisted ventilation, and subject submitted to hemodynamic monitoring.

- Use of beta-lactams (cefepime and meropenem). Myocardial infarction with global anoxia:

- Suppression syndromes.

- Delirium (non-convulsive crises?).

\section{Management}

- MDZ: initial $0.2 \mathrm{mg} / \mathrm{kg}$ IV in 2-5 min, repeat in bolus of $0.2-0.4 \mathrm{mg}$ every $5 \mathrm{~min}$ until the seizure stops. Maintenance at $0.05-2.9 \mathrm{mg} / \mathrm{Kg} / \mathrm{h}$.

- Propofol: initial 1-2 mg/kg IV in 3-5 min, repeat bolus every 3-5 min until the seizure stops. Initial infusion at $20 \mathrm{mcg} / \mathrm{kg} /$ minute, with maintenance of 30-200 $\mathrm{mcg} / \mathrm{Kg} / \mathrm{minute}$.

- VPA: $40 \mathrm{mg} / \mathrm{Kg}$ IV with an additional $20 \mathrm{mg} / \mathrm{kg}$, maintenance of $40 \mathrm{mg} / \mathrm{kg} / \mathrm{day}$.

- Pentobarbital: initial $5 \mathrm{mg} / \mathrm{kg}$ IV up to $50 \mathrm{mg} /$ minute, repeat in bolus of $5 \mathrm{mg} / \mathrm{kg}$ until the seizure stops, maintenance of $0.5-10 \mathrm{mg} / \mathrm{kg} / \mathrm{h}$ (Tables $6-9$ ).

- Ketamine: $1-2 \mathrm{mg} / \mathrm{kg}$ IV in 1 minute, maintenance of $0.01-0.03 \mathrm{mg} / \mathrm{kg} / \mathrm{minute}$ IV (adjust in the case of hepatic insufficiency).

- Corticosteroids: It is recommended especially in cases of super-refractory cases associated with Hashimoto's encephalitis or Rasmussen's encephalitis. 
A ketogenic diet could be an alternative, especially for children with catastrophic epilepsy. Vagus nerve stimulation is another alternative for super-refractory SE in children with catastrophic epilepsy.

Hemispherectomy is used in children with Rasmussen's encephalitis.

\section{What type of patient follow-up must be carried out after remission from SE?}

About two-thirds of the patients respond to the first treatment if it was opportune and adequate. In general, the prognosis for those patients is good and, with a good selection of anti-epileptic drugs to individualize the diagnostic approach to the patient, good control of the seizure can be achieved. Patient management and observation must be maintained, as with any individual that suffers from epilepsy. Unfortunately, between 3 and $33 \%$ die from the SE itself or the complications caused by this problem.

\section{References}

1. Trinka $E$, Cock $H$, Hesdorffer $D$, et al. A definition and classification of status epilepticus report of the ILAE task force on classification of status epilepticus. Epilepsia 2015;56:1515-23
3. Meierkord $\mathrm{H}$, Boon $\mathrm{P}$, Engelsen $\mathrm{B}$, et al. EFNS guideline on the management of status epilepticus in adults. Eur J Neurol. 2010;17:348-55.

2. Brophy GM, Bell R, Claassen J, et al. Guidelines for the evaluation and management of status epilepticus. Neurocrit Care. 2012;17:3-23.

4. Meierkord $\mathrm{H}$, Boon $\mathrm{P}$, Engelsen $\mathrm{B}$, et al. EFNS guideline on the management of status epilepticus. Eur J Neurol. 2006;13:445-50.

5. Glauser T, Shinnar S, Gloss D, et al. Evidence-based guideline: treatment of convulsive status epilepticus in children and adults: report of the guideline committee of the American epilepsy society. Epilepsy Curr. 2016;16:48-61.

6. Treiman DM, Meyers PD, Walton NY, et al. A comparison of four treatments for generalized convulsive status epilepticus. Veterans affairs status epilepticus cooperative study group. N Engl J Med. 1998;339:792-8.

7. Alldredge BK, Gelb AM, Isaacs SM, et al. A comparison of lorazepam, diazepam, and placebo for the treatment of out-of-hospital status epilepticus. N Engl J Med. 2001;345:631-7.

8. Mayer SA, Claassen J, Lokin J, et al. Refractory status epilepticus: frequency, risk factors, and impact on outcome. Arch Neurol. 2002;59:205-10.

9. Bleck TP. Management approaches to prolonged seizures and status epilepticus. Epilepsia. 1999;40, s59-s63.

10. Yasiry $Z$ and Shorvon SD. The relative effectiveness of five antiepileptic drugs in treatment of benzodiazepine-resistant convulsive status epilepticus: a meta-analysis of published studies. Seizure. 2014;23(3):167-74.

11. Lowenstein DH, Alldredge BK. Status epilepticus. N Engl J Med. 1998; 338:970-6.

12. Appleton R, Choonara I, Martland T, et al. The treatment of convulsive status epilepticus in children. Arch Dis Childhood. 2000;83:415-9.

13. Kinney MO, Craig JJ, Kaplan PW. Non-convulsive status epilepticus: mimics and chameleons. Pract Neurol. 2018;18:291-305.

14. Lowenstein $\mathrm{DH}$, Alldredge BK. Status epilepticus at an urban public hospital in the 1980s. Neurology. 1993;43:483-8.

15. Young GB, Jordan KG, Doig GS. An assessment of nonconvulsive seizures in the intensive care unit using continuous EEG monitoring: an investigation of variables associated with mortality. Neurology. 1996;47: 83-9.

16. Holtkamp M, Othman J, Buchheim K, Meierkord H. Predictors and prognosis of refractory status epilepticus treated in a neurological intensive care unit. J Neurol Neurosurg Psychiatry. 2005;76:534-9.

17. Holtkamp M, Othman J, Buchheim $\mathrm{K}$, et al. A "malignant" variant of status epilepticus. Arch Neurol. 2005;62:1428-31.

18. Vasquez A, Farias-Moeller R, Tatum W. Pediatric refractory and super-refractory status epilepticus. Seizure. 2018:S1059-311. 